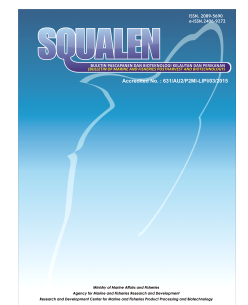

\title{
COMPOSITION OF FATTY ACIDS IN EVALUATION OF SEA CUCUMBER POTENCY FOR NUTRACEUTICAL PRODUCT DEVELOPMENT
}

\author{
Rini Susilowati ${ }^{1,}$, Asri Pratitis ${ }^{1}$, and Hedi Indra Januar ${ }^{1,2}$ \\ ${ }^{1}$ Research and Development Center for Marine and Fisheries Product Competitiveness and Biotechnology \\ Jalan KS Tubun Petamburan VI, Central Jakarta, Indonesia 10260; \\ 2 Department of Marine Science, Faculty of Fisheries and Marine Science, Bogor Agricultural University, Jalan Raya Dramaga, \\ Kampus IPB, Bogor, Indonesia 16680 \\ Article history: \\ Received: 1 May 2016; Revised: 10 June 2016; Accepted: 24 July 2016
}

\begin{abstract}
Unsaturated fatty acid in food has an effect to improve human health, while saturated fatty acid has the opposite impact. Ratio between both types of fatty acids is important to evaluate the biological material for nutraceutical product development. This paper aimed to evaluate the nutraceutical potency of sea cucumber from Kendari Bay Waters, South East Sulawesi, based on their fatty acids composition. The analysis was conducted by the ${ }^{1} \mathrm{H}-\mathrm{NMR}$ (Hidrogen-Nuclear Magnetic Resonance) method. Several species within 4 genera (Holothuria, Bohadschia, Actinopyga, and Stichopus) were selected as the subject of the study. Comparison of fatty acid composition has been done in genera level, the preliminary study found that variation between species among the same genera was insignificant $(p>0.05)$. Results of the study detected that Holothuria contained with an even ratio of Poly Unsaturated Fatty Acids (PUFA) and Saturated Fatty Acids (SFA), but Actinopyga was detected with low PUFA/SFA ratio. It may suggest that Holothuria from this region is the most potential raw material for nutraceutical product development. Meanwhile, precaution is needed for genera that contained with low PUFA/SFA ratio. Furthermore, comparison with other studies detected that fatty acids composition is not morphological specific, but vary, according to food viability, environmental and geographic location. Therefore, preliminary screening is important in evaluation of sea cucumber material for nutraceutical product development.
\end{abstract}

Keywords: 1H-NMR, fatty acids, sea cucumber, nutraceutical

\section{Introduction}

The increasing of global health care makes nutraceuticals as an alternative from medicines. Growth value of nutraceuticals globally has reached 180 million USD (Kim, 2013). There are several nutraceutical products that derived from marine organism. Marine biota, i.e. fish, oyster, seaweed, and microalgae, is a potential raw material for nutraceutical product that contains protein, fatty acids, antioxidants, minerals, and other food supplements (Venugopal, 2008). Among those species, sea cucumber is a marine organism that potential to be developed as nutraceutical product. Sea cucumber is believed containing medicinal properties for Asian over the last centuries (Wen et al., 2016). Natural product studies have detected a wide range of sea cucumber bioactivity, including anti-cancer, anti-coagulant, antihypertension, anti-inflammatory, anti-microbial, antioxidant, and anti-thrombotic (Bordbar, Anwar \& Saari, 2011).
Fatty acids are important properties in sea cucumber. Sea cucumber contains essential fatty acids, such as PUFA eicosapentaenoic acid, arachidonic acid and docosahexaenoic acid (Yahyavi et al., 2012). There is evidence about effectivity of PUFA treatment on cardiovascular disease from laboratory experiments and clinical trials (Harris et al., 2009; Marchioli et al., 2002; Mozaffarian \& Wu, 2011; Ridhowati, 2015). However, sea cucumber is also contained with SFA. On the contrary, high level of SFA is known to increase the risk of cardiovascular disease by raising the total cholesterol level (Hooper et al., 2011; Kris-Etherton, 1999). The optimal ratio of PUFA and SFA in food diets is 1.0-1.5 and should not below 1 or beyond 2 (Chang \& Huang, 1998; Kang, Shin, Park \& Lee, 2005). PUFA/SFA from a specific sea cucumber species may vary, as composition of fatty acids depends upon many factors (Wen et al., 2016; Xu, Xu, Zhang, Peng \& Yang, 2016; Zhang, Liu, Li \& Zhao, 2016). Therefore, analysis of fatty acid composition is an important pre-screening 
in the development of sea cucumber as nutraceutical products on a particular location. A sea cucumber which has a close of optimal PUFA/SFA ratio has a potency to be used as raw material for nutraceutical product development, while a species with high or low PUFA/SFA ratio should be avoided as nutraceutical raw material, as it may have contrary effects of nutraceuticals purpose.

An efficient analysis of fatty acid composition has been developed in the recent years, mainly with gas chromatography (GC) technique. Flame Ionization Detector (FID) and Mass Spectrometer (MS) tandem with $\mathrm{GC}$ are the instruments that are commonly used to analyze fatty acid composition in a particular organic sample. However, fatty acid analysis by chromatography technique requires a considerable amount of time and skillful chemist. Derivatization is a critical preparation step that needs to be done carefully in GC analysis of fatty acids (Yurchenko, Sats, Poikalainen \& Karus, 2016). Rapid and accurate method is needed to define PUFA/SFA ratio in a large batch of samples screening. Hidrogen-Nuclear Magnetic Resonance ( $\left.{ }^{1} \mathrm{H}-\mathrm{NMR}\right)$ is a prospective alternative for $\mathrm{GC}$ analysis in the quantification of fatty acid ratio. NMR is a rapid, reliable, efficient, and nondestructive analytical technique in an organic compound (Choudhary, Sharma \& Singh, 2016). Moreover, the time-consuming derivatization step is not needed in ${ }^{1} \mathrm{H}-\mathrm{NMR}$ analysis. This paper presents the application of ${ }^{1} \mathrm{H}$-NMR in PUFA/SFA analysis to evaluate the nutraceutical potency of sea cucumber from Kendari Bay Waters, South East Sulawesi.

\section{Material and Methods}

Ten species of sea cucumber samples were collected by SCUBA diving from Kendari Bay, South East Sulawesi. Taxonomical identification was conducted by Biosystematic and Biodiversity Lab, Faculty of Fisheries and Marine Science, Bogor Agricultural University. Taxonomical analysis identified that 10 sea cucumber samples from Kendari Bay belongs to 4 sea cucumber genera; Actinopyga (Actinopyga echinites and Actinopyga lecanora), Bohadschia (Bohadschia argus and Bohadschia marmorata), Holothuria (Holothuria atra, Holothuria edulis, Holothuria hilla, and Holothuria nobilis), and Stichopus (Stichopus hermanni and Stichopus variegatus). Actinopyga, Bohadschia, and Holothuria are genera of Holothuridae family, while Stichopus is a genus of Stichoporidae family.

Raw samples were cleaned, their body fluids were removed, and body walls of the samples were preserved in a cool-box containing of ice for transporting to the laboratory in Jakarta, DKI Jakarta Province. Extraction of fatty acids was conducted according to the method of Bligh and Dyer (1959). Total fat extraction was made in 5 replications, each extraction using $100 \mathrm{~g}$ of fresh sample. Solvent in the fatty acids fraction was evaporated by freeze dryer (vaccum concentrator). Total fatty acids were determined by gravimetric measurement. Aliquot of $50 \mathrm{mg}$ lipid extracts from each sample was dissolved in $0.7 \mathrm{ml}$ of $\mathrm{CDCl}_{3}$ (contained with $0.2 \%$ non-deuterated chloroform and small amount of tetramethylsilane as internal reference).

${ }^{1} \mathrm{H}-\mathrm{NMR}$ analysis was performed on Jeol Spectrometer $400 \mathrm{MHz}$. Acquisition parameters were selected according to Guillen and Uriarte (2009); 400 $\mathrm{MHz}$, 3s relaxation delay, 64 numbers of scans, and 90 pulse width. The experiment was carried out at room temperature $\left(20^{\circ} \mathrm{C}\right)$ with total acquisition time for each sample was $5 \mathrm{~min} 32 \mathrm{~s}$. Chemical shift values were reported in $\mathrm{ppm}$ by referencing them to tetramethylsilane. The signals $(A-F)$ used for quantitative analysis are presented in Figure 1. Range of each signal was referred to Castejón, MateosAparicio, Molero, Cambero and Herrera (2014), which were; $0.930-0.827$ ppm (signal A), $1.010-0.930$ ppm (signal B), 2.120-1.932 ppm (signal E), 2.357-2.248 ppm (signal F), 2.889-2.675 ppm (signal G), and 4.3734.070 ppm (signal $\mathrm{H}$ ). Compositions of fatty acids were calculated based on integral data extracted from each signal in the spectrum according to Castejón, Fricke, Cambero and Herrera (2016). Data of fatty acid composition were presented in genera level, as the preliminary study found variation between species on the same genera was insignificant $(p>0.05)$. Kruskall-Wallis and multivariate discriminant analysis were employed to analyze variation in fatty acid composition.

\section{Results and Discussion}

Total fat content and composition of fatty acid are presented in Figure 2. All of the samples were detected to contain with $0.03-0.12 \%$ fat. The fat content of different species in the same genera was not varied significantly $(p>0.05)$, with average deviation at $0.02 \%$. Significant difference was detected between genera $(p<0.05)$. Bohadschia genera had the lowest fat, while Stichopus contained the highest fat. These values are typical for sea cucumber, as the similar results to Wen et al. (2016) and Aydin, Sevgili, Tufan, Emre and Ko"se (2011) studies. Meanwhile, fatty acid composition of each observed sea cucumber genera was different. The relative deviation standard of fatty acid composition in each genus was in the range between 9 and $21 \%$. Statistical Kruskall-Wallis analysis of fatty acid composition revealed the same results as total fat content. Furthermore, similar to 


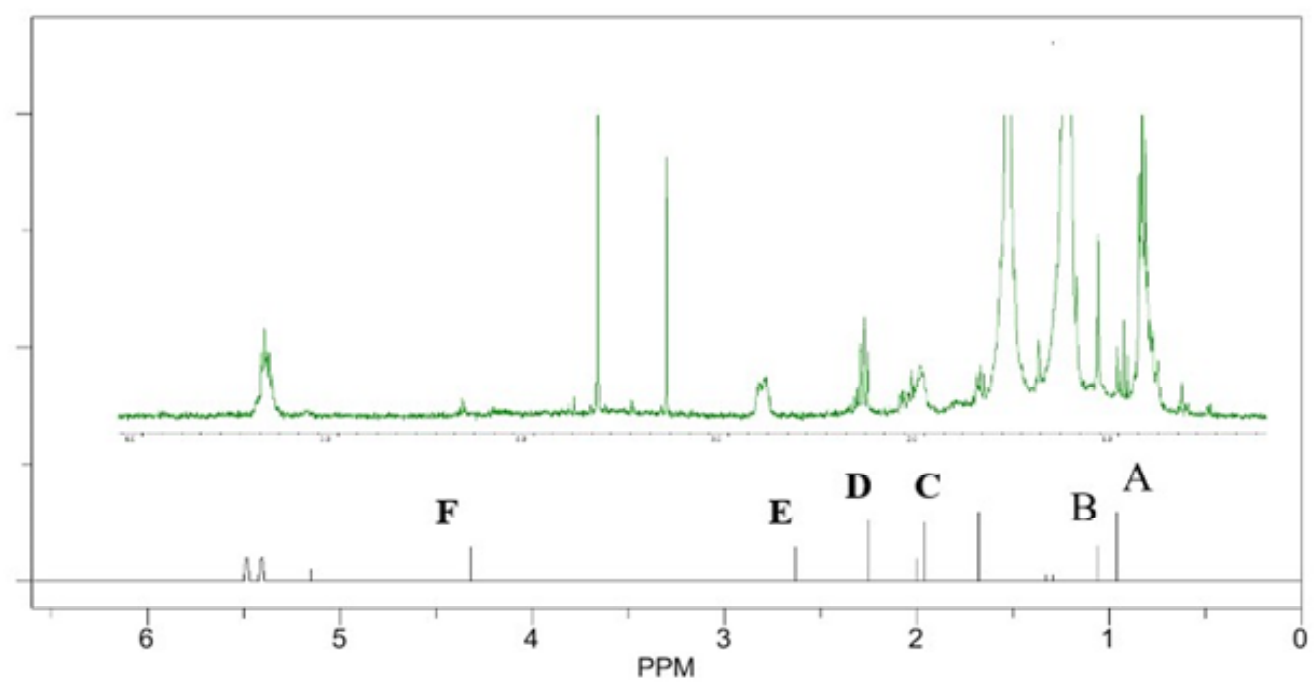

Figure 1. Chemical shift used for calculation of fatty acids composition in ${ }^{1} \mathrm{H}-\mathrm{NMR}$ spectrometry $\mathrm{SFA}=(4 \times \mathrm{A})+(4 \times \mathrm{B})-[3 \times(\mathrm{C} / 6) \times \mathrm{D}] ; \quad \mathrm{MUFA}=(4 \times \mathrm{B})+(3 \times \mathrm{C})-[6 \times(\mathrm{F} / 6) \times \mathrm{D}] ;$ PUFA $=(3 \times E)-[2 \times(B / 3) \times D]$.



Figure 2. Total fatty acids (a) and Poly Unsaturated Fatty Acids (PUFA), Mono Unsaturated Fatty Acids (MUFA), and Saturated Fatty Acids (SFA) composition (b) of sea cucumber from Kendari bay, South East Sulawesi (results presented as mean $\pm \mathrm{SD}$ ).

our preliminary study, composition in the same species was not significantly varied $(p>0.05)$, but significant difference between genera $(p<0.05)$. The insignificant results of fatty acid composition on the same species revealed the robustness of ${ }^{1} \mathrm{H}$-NMR in fatty acid analysis. Combined with its main advantages, such as simplicity and lack of need for sample pre-treatment, NMR is a reliable and fast screening method for fatty acid composition compares to other conventional methods (Barison et al., 2010).

Canonical discriminant analysis detected that composition of PUFA, MUFA, and SFA may separate the characteristics in each genus (Figure 3 ). Actinopyga contained with higher SFA, while
Bohadschia related with higher MUFA content. Futhermore, Holothuria had low MUFA and balanced composition between SFA and PUFA, while Stichopus detected to contain the highest number of PUFA. These results may overcome from homogeneity of overall environmental condition in Kendari Bay. Nevertheless, the significant different of fatty acid composition is shown between sea cucumber genera. Fatty acid composition in sea cucumber is known to relate with habitat feeding behavior (Wen et al., 2016; Zhang et al., 2016). Therefore, it may suggest that food viability of each sea cucumber genera habitat was different.

However, this pattern may only apply to a particular location. Statistical analysis that compared the fatty 


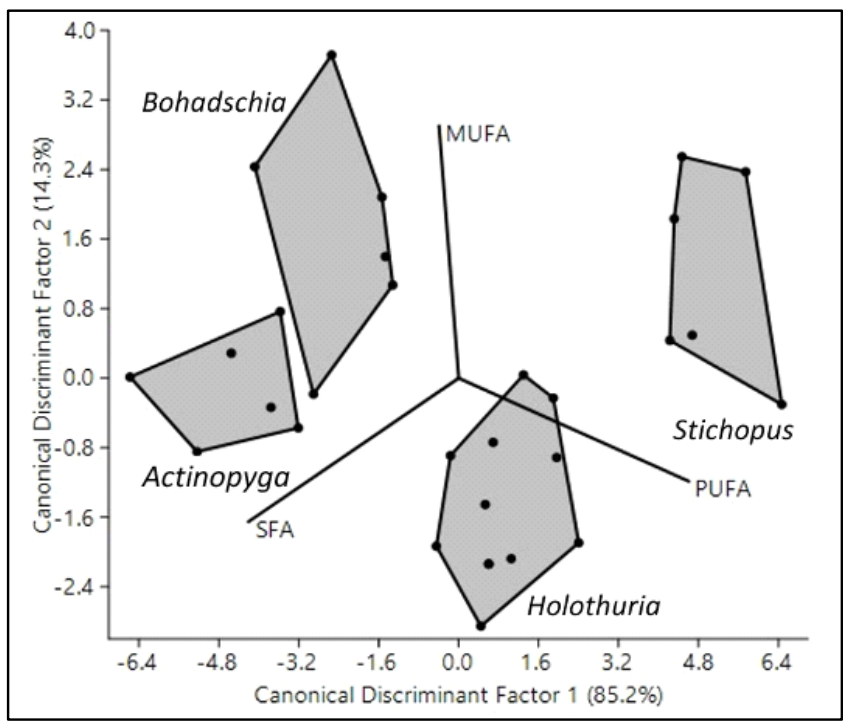

Figure 3. Canonical discriminant analysis (CDA) of composition of Poly Unsaturated Fatty Acids (PUFA), Mono Unsaturated Fatty Acids (MUFA), and Saturated Fatty Acids (SFA) of sea cucumber from Kendari Bay, South East Sulawesi.

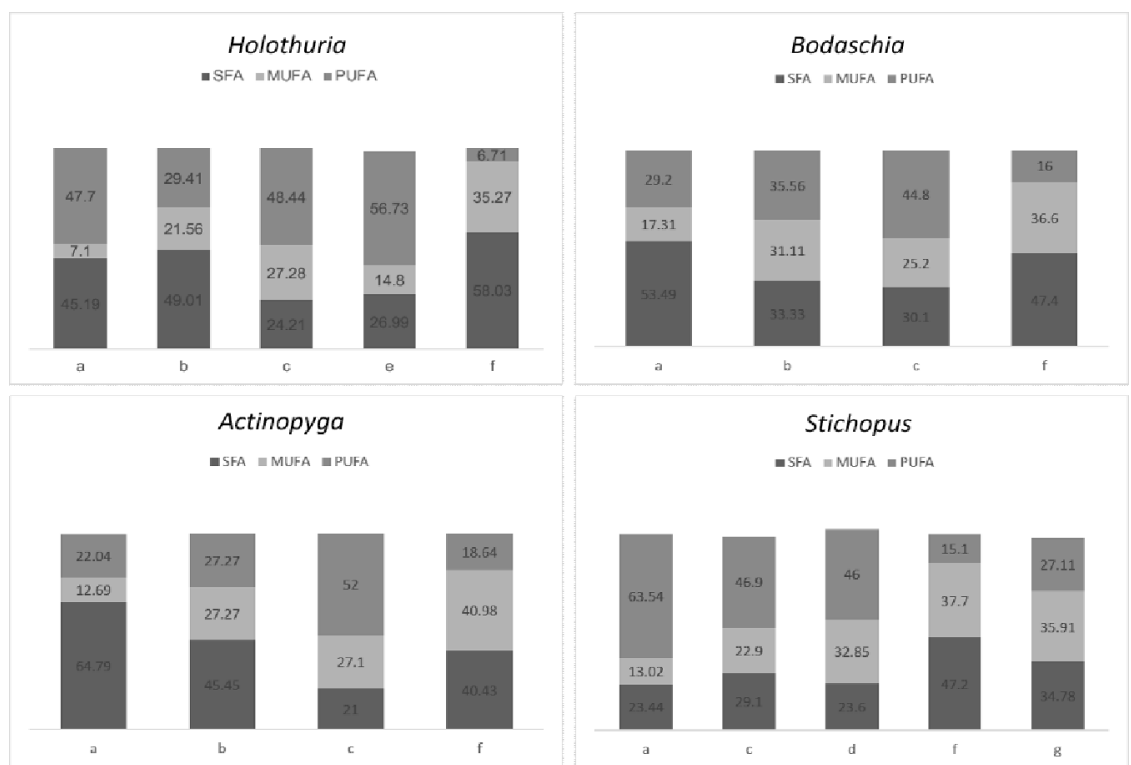

Note: Kendari Bay Indonesia-current study, (b) Halmahera waters Indonesia - Fawyza, Januar, Susilowati and Chasanah (2015), (c) Vietnam - Svetashev, Levin, Lam and Nga (1991), (d) Japan-Svetashev et al. (1991), (e) Turkey - Aydin et al. (2011), (f) China-Wen et al. (2010), (g) Japan-Kasai (2003), (h) China-Gao et al. (2016).

Figure 4. Fatty acids composition (\%) of Holothuria, Bohadscia, Actinopyga, and Stichopus from different locations.

acid composition of Kendari Bay sea cucumber to other studies revealed that the pattern of fatty acid composition is no $t$ taxonomical dependence (Figure 4). Various compositions without any clear pattern shown between the same genera of sea cucumber.
CDA showed the geographical habitat dependence of fatty acid composition in sea cucumber Holothuria (Figure 5). Holothuria from Kendari Bay had higher content of SFA, while Turkey Holothuria (Aydin et al., 2011) contained with higher PUFA. On the other hand, 


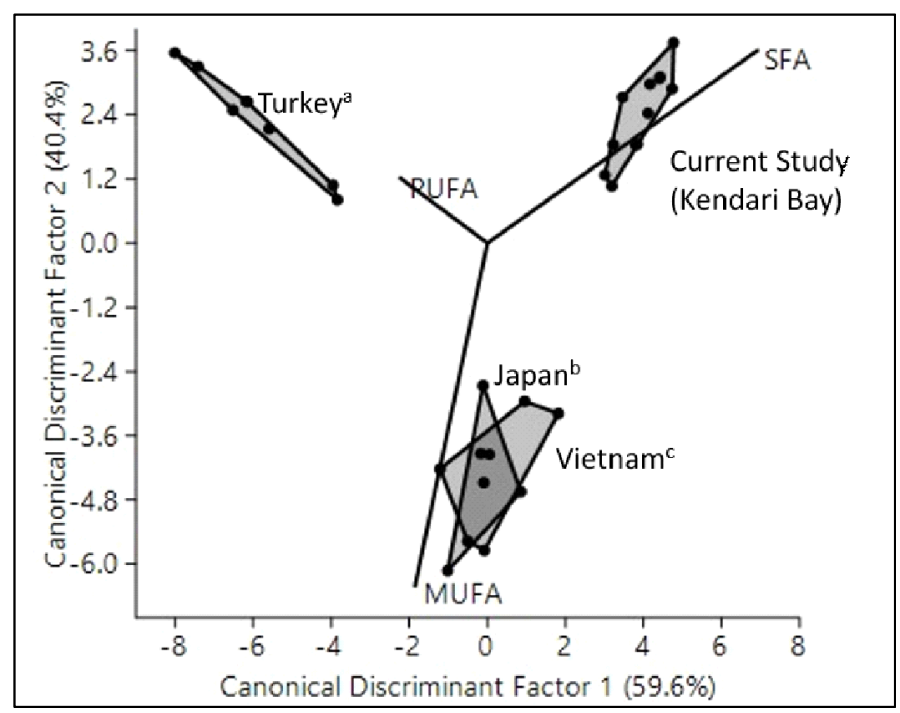

Figure 5. Canonical discriminant analysis (CDA) to composition of Poly Unsaturated Fatty Acids (PUFA), Mono Unsaturated Fatty Acids (MUFA), and Saturated Fatty Acids (SFA) of sea cucumber genera Holothuria from Kendari Bay - South East Sulawesi, (a) Turkey - Aydin et al. (2011), (b) JapanKasai (2003), and (c) Vietnam - Svetashev et al. (1991).

both Holothuriafrom Japan (Kasai, 2003) and Vietnam (Svetashev, Levin, Lam \& Nga, 1991) were contained higher MUFA composition.

All of these results showed the importance of preliminary screening in PUFA/SFA ratio as an evaluation of sea cucumber potency as raw material in marine nutraceutical development. Various ratio of fatty acid composition may present in sea cucumber, which depends on environmental characteristics. Fatty acids have many functions and play a significant role in biochemistry of living being, such as osmoregulation, nutrient assimilation, and transport (Haliloçlu, Bayýr, Sirkecioçlu, Aras \& Atamanalp, 2004). However, on heterogeneity environmental characteristics, fatty acid content may differ significantly. Geographical location is shown to affect significantly to the fatty acid metabolite in sea cucumber species (Xu, Xu, Zhang, Peng \& Yang, 2016). As discussed previously, food viability in different habitat location affected significantly to fatty acids composition in sea cucumber.

Therefore, precautions on biological material selection are needed with the requirement of PUFA/ SFA ratio at 1.0-1.5 for development of nutraceutical raw extract. Thus, Holothuria is the most prospective sea cucumber for nutraceutical products in Kendari Bay. The high content of PUFA in Stichopus from this region is more likely potential for omega 3-herbal drug products isolate. Meanwhile, Kendari Bay Actinopyga and Bohadschia have the lowest potency as nutraceuticals, as it detected to have unbalanced PUFA/SFA ratios, with high level of SFA.

\section{Conclusion}

This study indicated that fatty acid composition in sea cucumber might be different within taxonomical, geographical location, habitat, and feeding behavior variation. Therefore, as the needs of 1.0-1.5 PUFA/ SFA ratio, preliminary screening of fatty acid composition is needed for evaluation of sea cucumber potency as raw material in marine nutraceutical development. Further study directed to nutraceutical development of the of Holothuriagenera from Kendari Bay.

\section{Acknowledgment}

We acknowledge and also grateful to Dr. B. Sadarun SP.MS, lecturer of Faculty of Marine and Fisheries, University of Haluoleo and Dr. Kustiariyah Tarman, the researcher of Center for Coastal and Marine Resources Studies, IPB for technical support and helping with sample collection.

\section{References}

Aydýn, M., Sevgili, H., Tufan, B., Emre, Y., \& Ko“se, S. (2011). Proximate composition and fatty acid profile of three different fresh and dried commercial sea cucumbers from Turkey. International Journal of Food Science and Technology, 46, 500-508.

Barison, A., Silva, C.W.P., Campos, F.R., Simonelli, F., Lenz, C.A., \& Ferreira, A.G. (2010). A simple methodology for the determination of fatty acid composition inedible oils through ${ }^{1} \mathrm{H}-\mathrm{NMR}$ spectroscopy. Magnetic Resonance Chemistry, 48, 642-650. 
Bligh E.G and Dyer W.J. (1959). A rapid method of total lipid extraction and purification. Canadian Journal of Biochemistry and Physiology , 27(8); 912-917.

Bordbar, S., Anwar, F., \& Saari, N. (2011). High-value components and bioactives from sea cucumbers for functional foods - a review. Marine drugs, 9 (10), 17611805.

Castejón, D., Mateos-Aparicio, I., Molero, M.D., Cambero, M.I., \& Herrera, A. (2014) Evaluation and optimization of the analysis of fatty acid types in edible oils by $1 \mathrm{H}$ NMR. Food Analytical Methods, 7, 1285-1297.

Castejón, D., Fricke, P., Cambero, M. I., \& Herrera, A. (2016). Automatic $1 \mathrm{H}-\mathrm{NMR}$ screening of fatty acid composition in edible oils. Nutrients, 8(2), 93.

Chang, N.W. \& Huang, P.C. (1998). Effects of the ratio of polyunsaturated and monounsaturated fatty acid to saturated fatty acid on rat plasma and liver lipid concentrations. Lipids, 33(5), pp.481-487.

Choudhary, A., Sharma, R.J., \& Singh, I.P., (2016). Determination of major sesquiterpene lactones in essential oil of Inula racemosa and Saussurea lappa using qNMR. Journal of Essential Oil Bearing Plants, 19(1), 20-31.

Fawzya, Y.F., Januar, H.I., Soesilowati, R., \& Chasanah, E. (2015). Chemical composition and fatty acids profile of some Indonesian sea cucumber. Squalen Bulletin of Marine Fisheries Postharvest \& Biotechnology, 10(1), 27-34.

Gao, Y., Li, Z., Qi, Y., Guo, Z., Lin, Y., Li, W., Huc, Y., \& Zhao, Q. (2016). Proximate composition and nutritional quality of deep sea growth sea cucumbers (Stichopus japonicus) from different origins. Journal of Scientific Food Agricultural, 96, 2378-2383.

Guillen, M.D., \& Uriarte, P.S. (2009). Contribution to further understanding of the evolution of sunflower oil submitted to frying temperature in a domestic fryer: study by $1 \mathrm{H}$ nuclear magnetic resonance. Journal Agricultural Food Chemistry, 57, 7790-7799.

Haliloçlu, H. Ý., Bayýr, A., Sirkecioçlu, A. N., Aras, N. M., \& Atamanalp, M. (2004). Comparison of fatty acid composition in some tissues of rainbow trout (Oncorhynchus mykiss) living in seawater and freshwater. Food Chemistry, 86(1), 55-59.

Harris, W.S., Mozaffarian, D., Rimm, E., Kris-Etherton, P., Rudel, L.L., Appel, L.J., Engler, M.M., Engler, M.B. \& Sacks, F. (2009). Omega-6 fatty acids and risk for cardiovascular disease a science advisory from the American Heart Association Nutrition Subcommittee of the Council on Nutrition, Physical Activity, and Metabolism; Council on Cardiovascular Nursing; and Council on Epidemiology and Prevention. Circulation, 119 (6), 902-907.

Hooper, L., Summerbell, C.D., Thompson, R., Sills, D., Roberts, F.G., Moore, H., \& Davey-Smith, G. (2011). Reduced of modified dietary fat for preventing cardiovascular disease. Cochrane Database of Systematic Reviews, DOI:10.1002/ 14651858. CD002137.pub2.

Kang, M.J., Shin, M.S., Park, J.N. \& Lee, S.S. (2005). The effects of polyunsaturated: saturated fatty acids ratios and peroxidisability index values of dietary fats on serum lipid profiles and hepatic enzyme activities in rats. British Journal of Nutrition, 94 (04), 526-532.

Kim, S. K. (2013). Marine nutraceuticals: prospects and perspectives. CRC Press. 464 p.

Kasai, T. (2003). Lipid Contents and Fatty Acid Composition of Total Lipid of Sea Cucumber Stichopus japonicus and Konowata (Salted Sea Cucumber Entrails). Food Science \& Technology Resources, 9(1), 45-48.

Kris-Etherton, P. M. (1999). Monounsaturated fatty acids and risk of cardiovascular disease. Circulation, 100(11), 1253-1258.

Marchioli, R., Barzi, F., Bomba, E., Chieffo, C., Di Gregorio, D., Di Mascio, R., Franzosi, M.G., Geraci, E., Levantesi, G., Maggioni, A.P. \& Mantini, L. (2002). Early protection against sudden death by $n-3$ polyunsaturated fatty acids after myocardial infarction time-course analysis of the results of the Gruppo Italiano per lo Studio della Sopravvivenza nell'Infarto Miocardico (GISSI)Prevenzione. Circulation, 105(16), 1897-1903.

Mozaffarian, D., \& Wu, J.H. (2011). Omega-3 fatty acids and cardiovascular disease: effects on risk factors, molecular pathways, and clinical events. Journal of the American College of Cardiology, 58(20), 20472067.

Ridhowati, S. (2015). Amino acids and fatty acids profile of processed Holothuria scabra sea cucumber from Belitung Waters. Indonesian Journal of Mathematics, Science, and Technology, 16(2), 20-27.

Svetashev, V.I., Levin, V.S., Lam, C.M., \& Nga, D.T. (1991). Lipid and fatty acid composition of Holothurians from tropical and temperate waters. Computational Biochemistry \& Physiology, 98B(4), 489-494.

Venugopal, V. (2008). Marine products for healthcare: functional and bioactive nutraceutical compounds from the ocean. CRC press. $528 p$

Wen, B., Gao, Q.F., Dong, S.L., Hou, Y.R., Yu, H.B. \& Xi, X. (2016). Absorption of different macroalgae by sea cucumber Apostichopus japonicus (Selenka): Evidence from analyses of fatty acid profiles. Aquaculture, 451, 421-428.

Xu, Q., Xu, Q., Zhang, X., Peng, Q. \& Yang, H. (2016). Fatty acid component in sea cucumber Apostichopus japonicus from different tissues and habitats. Journal of the Marine Biological Association of the United Kingdom, 96(1), 197-204.

Yahyavi, M., Afkhami, M., Javadi, A., Ehsanpour, M., Khazaali, A., \& Mokhlesi, A. (2012). Fatty acid composition in two sea cucumber species, Holothuria scabra and Holothuria leucospilata from Qeshm Island (Persian Gulf). African Journal of Biotechnology, 11(12), 2862-2868.

Yurchenko, S., Sats, A., Poikalainen, V. \& Karus, A. (2016). Method for determination of fatty acids in bovine colostrum using GC-FID. Food Chemistry, 212, 117122.

Zhang, X., Liu, Y., Li, Y. \& Zhao, X. (2016). Identification of the geographical origins of sea cucumber (Apostichopus japonicus) in northern China by using stable isotope ratios and fatty acid profiles. Food Chemistry, 218, 269-276. 